DOI: 10.12731/2658-4034-2020-1-54-63

\title{
ФОРМИРОВАНИЕ УМЕНИЙ В ТЕХНИКЕ ВЫПУКЛОЙ ГРАВЮРЫ У УЧАЩИХСЯ ДХШ
}

\section{Романова О.A.}

Владимирский Государственный Университет

им. А.Г. и Н.Г. Столетовых, г. Владимир, Российская Федерация

В данной статье рассматривается проблема недостаточного обеспечения конкретными методическими разработками по обучению выпуклой гравюры учашихся детских художественных школ. Целью является выявление особенностей техники выпуклой гравюры для определения методики формирования умений у обучаемых. B cmатье приведены базовые и специальные упражнения, способствующие эффективному освоению учашимися техники выпуклой гравюры.

Методом проведения работы является изучение, анализ, обобщение научных источников и учебных программ дополнительного образования по рассматриваемой проблеме. Также проводятся блоки упражнений на получение знаний, умений и навыков по изучаемому разделу.

Результаты работы: выполнен отбор содержания учебного материала на освоение техники выпуклой гравюры, разработаны блоки базовых и специальных упражнений для эффективного усвоения учащимися дошкольного образования названной техники.

Область применения результатов: сфера дополнительного художественного образования.

Предлагаемая методика по формированию умений при выполнении системы упражнений позволяет учащимся освочть приемы (упражнения) смешанной техники для упрощчения процесса создания творческой работьл.

Ключевые слова: печатная графика; выпуклая гравюра; линогравюра; пластик; печать. 


\title{
FORMATION OF SKILLS \\ IN THE TECHNIQUE OF CONVEX ENGRAVING IN PUPILS OF THE SCHOOL OF ART
}

\section{Romanova O.A.}

\author{
Vladimir State University named after Alexander \\ and Nikolay Stoletovs, Vladimir, Russian Federation
}

This article discusses the problem of insufficient provision of specific methodological developments for teaching convex engravings to students of children's art schools. The goal is to identify the features of convex engraving techniques to determine the methodology for the formation of skills of students. The article provides basic and special exercises that contribute to the effective development of convex engraving techniques by students.

The method of work is the study, analysis, generalization of scientific sources and curricula of continuing education on the issue. Also, blocks of exercises for obtaining knowledge, skills in the studied section are conducted.

Results of the work: the selection of the content of educational material for the development of convex engraving techniques was completed, blocks of basic and special exercises were developed for the effective assimilation by students of preschool education of the named technique.

The scope of the results: the scope of additional art education.

The proposed methodology for the formation of skills in the exercise system allows students to master the techniques (exercises) of mixed technology to simplify the process of creating creative work.

Keywords: printed graphics; convex engraving; linocut; plastic; printing.

В работе художника над выпуклой гравюрой при создании произведения ключевую роль играют сформированные навыки и умения в данной технике. Эта же задача стоит перед педагогом 
в процессе обучения детей технике высокой печати. Для формирования у учащихся умения работать над выпуклой гравюрой, необходимо определить содержательную сторону обучения. Для этого нужно проанализировать художественную литературу и опыт работы великих художников-мастеров, таких как Бочкин А.Н., Рузин В.И., Терегулов А.Р., Кругликова Е.С., Бородин А.В., Щегольков М.И.

Гравюра - самый молодой из видов изобразительного искусства, демократичный и массовый вид творчества. Если зарождение живописи, рисунка, скульптуры, архитектуры происходит в доисторических эпохах, то появление гравюры более или менее точно известно 14-15 веков. (На Востоке и в Китае гравюра возникла еще в 8 веке) [1].

Гравюрой принято называть как доску, на которой вырезано, выгравировано изображение, так и отпечаток (оттиск) с нее. Оттиск называют еще и эстампом. Под словом «доска» в гравировальном искусстве понимают не только дерево, но и любой материал, на котором вырезана гравюра. Гравюра в истинном смысле слова, как отпечаток на бумаге изображения, вырезанного на специальной доске, появляется именно на рубеже 14-15 веков. Это исключительное для истории явление, рождение нового вида искусства, обусловлено технологическими, эстетическими и социальными причинами. Для того что бы гравюра развивалась нужно чтоб появился новый подходящий и легкодоступный материал, на котором она могла гравироваться и печататься. Только с широким распространением бумаги гравюра обрела основу своей технологии - податливый, легко принимающий на себя различного рода изображения, дешёвый материал [2].

Гравюра обладает особым свойством, в наибольшей степени отличающим ее от всех других видов изобразительного искусства. Это свойство - тиражность. Изобразительное искусство развивает в себе тенденции натуральности, зрительной точности и убедительности развивает в первую очередь живопись, а гравюра принимает на себя качества символически, отвлеченности. 
Гравюры бывают двух типов - выпуклые и углубленные. В выпуклой гравюре рисунок оставляется в виде рельефа, а все белые места углубляются резцами. В углубленной гравюре на оборот, основная плоскость доски соответствует будущему белому полю, а собственно в рисунке прорезают углубление, которые при печати и заполняются краской. Печатание с выпуклых форм называется высокой печатью, а углубленных - глубокой печатью.

К выпуклой гравюре можно отнести линогравюру и гравюру на пластике. Изобразительные и выразительные возможности гравюры на пластике и линолеуме разнообразны и позволяют создать интересные и необычные образы. Использование художественных техник в выпуклой гравюре на пластике и линолеуме является эффективным средством для создания выразительности образов, для проявления и развития детской одарённости. Работая в этой технике, учащиеся ДХШ в графике развивают композиционное решение, логическое и пространственное мышление, формируют художественный вкус, развивают творческие способности, помогают выработать новые навыки и умения.

Технология работы выполнения гравюры на пластике тот же, что и в линогравюре: на гравировочной доске из пластика резцами различных форм и размеров вырезается перенесенный с кальки или копировальной бумаги эскиз работы, далее накатывается валиком типографская краска на доску и производится печать через станок. Главным преимуществом гравюры на пластике является уникальная фактура на оттиске и резкие, четкие контрасты черного и белого за счет продавливания, и вырезания штрихов штихелями. А в линогравюре преимущественно используются тонкие детали и штрихи для придания большей выразительности изображению при помощи объема и светотени, средств выразительности. Пластик, как и линолеум, является доступным более легким для обучения материалом, позволяющим создать тонкие выразительные работы. Благодаря этому можно использовать для обучения гравюре учащимся дополнительного образования. 
В настоящее время за рубежом гравюра развивается гораздо более быстрыми темпами, нежели в России. Появляются новые приемы и смешанные техники выпуклой гравюры в исполнении работ на пластике и линолеуме. Применяются коллажи, принты, штампы и новые цветовые решения, происходит уход в декоративность или в более детализированную реальность [6]. Как показывают наблюдения, в ДХШ техника выпуклой гравюры мало раскрыта для обучающихся. Для популяризации данного направления требуется создать более углубленный курс по выпуклой гравюре. Это необходимо для дальнейшего развития в обучающихся, художественного вкуса и стиля, приобщения к художественной культуре и повышения уровня творческих способностей.

Графические умения работы в технике выпуклой гравюры будут развиваться у учеников при изучении углубленного курса в истории гравюры, новых приемов и методов гравирования с использованием новых материалов, и инструментов, базовых и специальных упражнений. В связи с этим целесообразно проанализировать методическую литературу отобрать новые решения и упражнения-задания.

Одним из источников информации по данному вопросу являются зарубежные издания, у которых нет аналогов в России. Например, Pressing matters paссказывает о мастерах и процессе создания графических работ. Показывает их уникальность и необычные методы, способы при выполнении в выпуклой гравюре. На этой основе можно произвести отбор специальных упражнений, направленных на освоение приемов гравирования и овладение особенностями работы резцами разных сечений и форм. В процессе обучения предполагается освоение учащимися общеизвестных приемов и способов использования оборудования, необходимого для работы, и выполнение серии упражнений для овладения основными умениями. Использование материалов издания поможет сформировать у учеников не только знания, умения и навыки, но и развить художественный вкус и стиль работы.

Прежде чем приступать к эскизу будущей работы, учащимся целесообразно выполнить упражнения для овладения основными уме- 
ниями работы штихелями разных форм. Специальные упражнения можно распределить на две группы по материалу.

Первая группа: линогравюра. В нее входят базовые упражнения на развитие начального навыка и специальные упражнения на совершенствование умений для создания специальных фактур, основанные на базовых упражнениях.

Базовые и специальные упражнения распределяются на блоки:

Блок №1- направлен на освоение основного приема резьбы; формирование умения в правильном положении держать штихель; освоение градации цвета, освоение штриховки; развитие глазомера для создания равномерных промежутков в упражнениях и творческой работе.

Блок №2 - направлен на формирование взаимодействия резца с материалами при вращении формы в разных направлениях; овладение равномерным нажимом на резец; умения твердо и правильно держать штихель.

Блок №3 - направлен на формирование умения применять разный нажим на штихель; формирование умения использовать штихели разных сечений.

Ниже представлена часть упражнений из блоков.

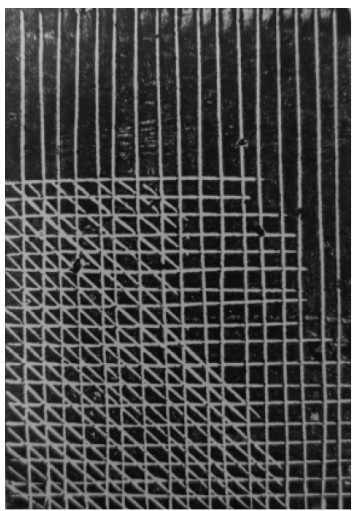

Рис. 1. Блок 1.

Перекрещивающиеся линии. Материал: линолеум

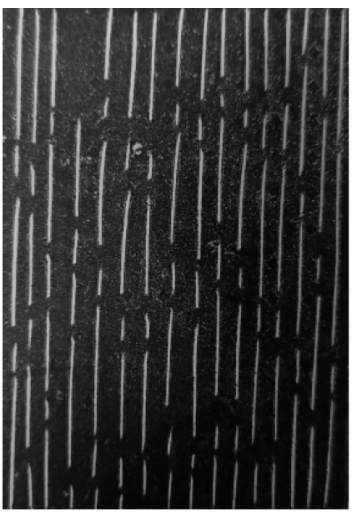

Рис. 2. Блок 1. Пунктир. Материал: линолеум

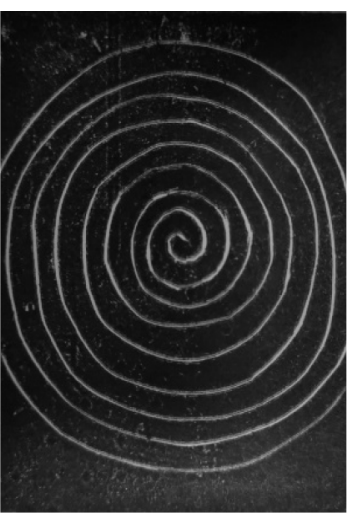

Рис. 3. Блок 2. Круг. Материал: линолеум 


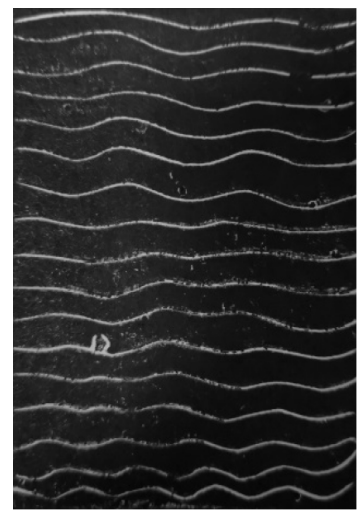

Рис. 4. Блок 2.

Волна. Материал: линолеум

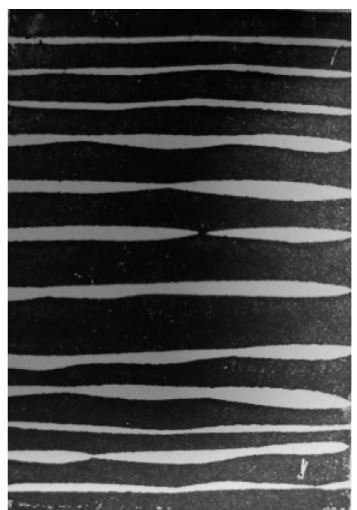

Рис. 5. Блок 3.

Вид нажима.

Материал: линолеум

Блок №4 - спещиальные упражнения формируют навыки применения базовых навыков для создания фактур; закрепляют умения владения штихелями разных сечений; формируют все освоенные умения базовых и специальных упражнений; помогают развить композиционное, логическое и пространственное мышление, формируют художественный вкус, развивают творческие способности, помогают выработать новые навыки и умения.

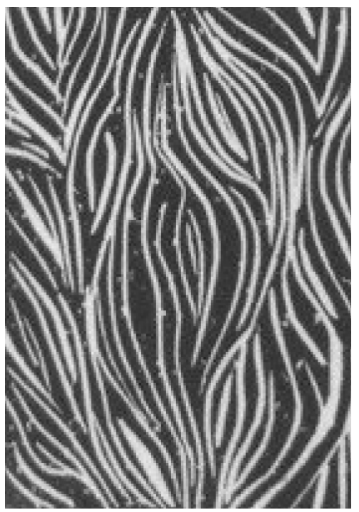

Рис. 1. Фактура дерева. Материал: линолеум

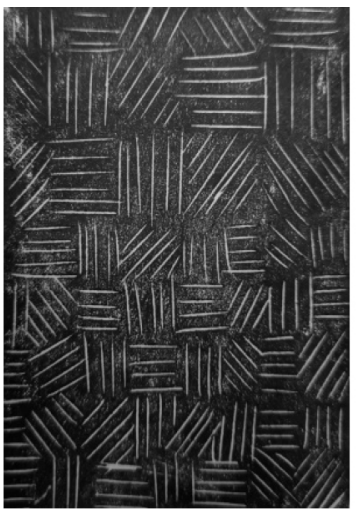

Рис. 2. Штрих.

Материал: линолеум

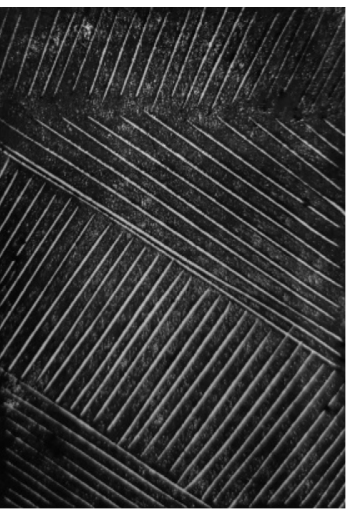

Рис. 3. Штрих.

Материал: линолеум 
Вторая группа: гравюра на пластике. Использование новых приемов с применением штихелей и инструментов, таких как: рулетка, шабер, колесико, игла. В группу входят базовые упражнения, направленные на развитие начального навыка работы с пластиком новыми инструментами разных форм и штихелями; специальные упражнения на улучшение умений, в основе которых лежат базовые упражнения на создание специальных фактур. Пластик - более легкий для обработки материал по сравнению с линолеумом. Главным преимуществом гравюры на пластике является уникальная фактура на оттиске и резкие, четкие контрасты черного и белого цветов за счет продавливания инструментами, и вырезания штрихов штихелями.

Блок №1 - направлен на освоение основного приема резьбы или продавливания; сформирование умения в правильном положении держать штихель или инструмент; освоение градации цвета.

Блок №2 - направлен на формирование умения осуществлять взаимодействие резца с материалами при вращении формы в разных направлениях; овладение равномерным нажимом на резец; умение твердо и правильно держать штихель.

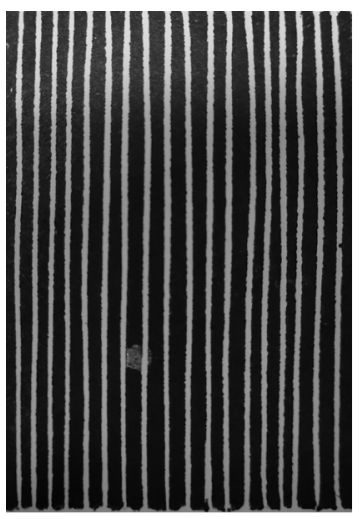

Рис. 1. Блок 1.

Прямые линии.

Материал: пластик

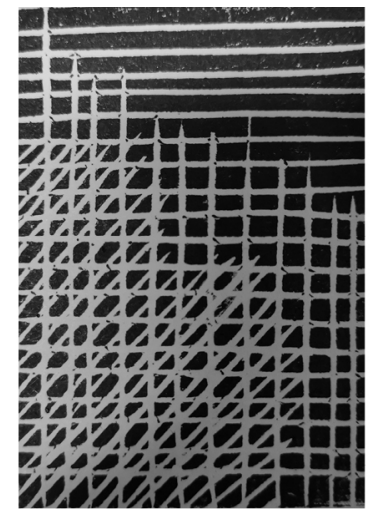

Рис. 2. Блок 1. Перекрещивающиеся линии. Материал: пластик

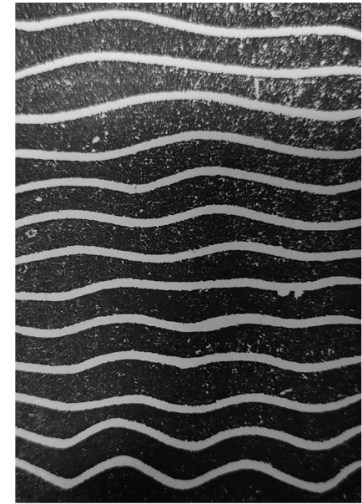

Рис. 3. Блок 2.

Волна. Материал: пластик

Блок №3 - направлен на формирование умения применять различные новые инструменты для выпуклой гравюры, такие как: ру- 
летка, шабер, колесико, игла; формирование умения использовать штихели разных сечений; освоение градации цвета; овладение равномерным нажимом на инструмент.

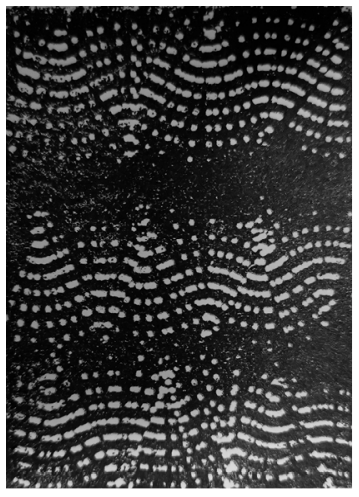

Рис. 4. Блок 3.

Веер. Материал: пластик

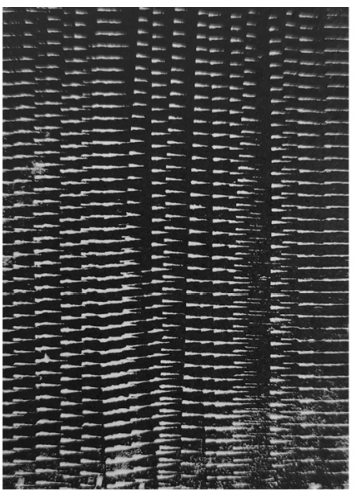

Рис. 5. Блок 3. Зебра. Материал: пластик

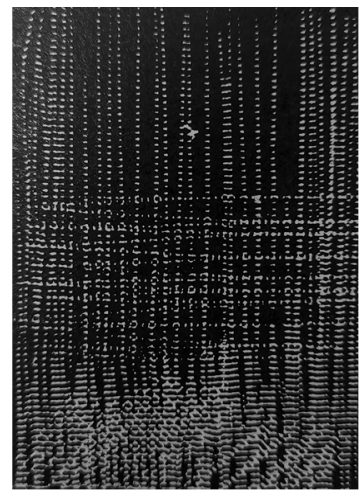

Рис. 6. Блок 3.

Перекрещивающиеся линии. Материал: пластик

Блок №4 - Спещиальные упражнения формируют умение применять базовые навыки при передаче фактур с помощью штихелей и инструментов (рулетка, шабер, колесико, игла); закрепляют умения владения штихелями и инструментами разных сечений; закрепляют освоенные умения базовых и специальных упражнений.

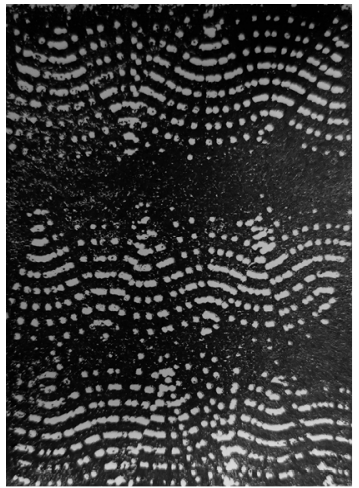

Рис. 1. Рябь.

Штрих. Материал: пластик

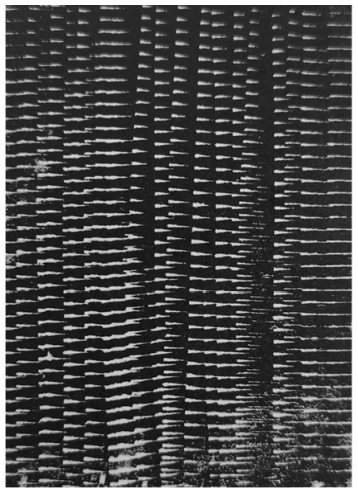

Рис. 2. Сетка.

Материал: пластик

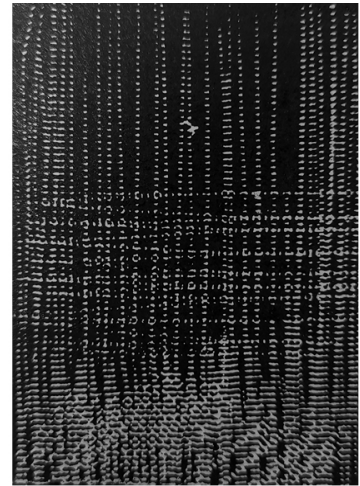

Рис. 3.

Градация тона. Материал: пластик 
Таким образом, в результате исследования установлено, что для формирования умений работы в технике выпуклой гравюры учащимся ДХШ необходимо освоить определённую в ходе исследования систему упражнений и заданий. Разработанная методика предусматривает успешное прохождение процесса обучения, поскольку опирается на специально отобранное содержание и логически выстроенную последовательность решения учебных задач.

\section{Список литературы}

1. Катафал Й. Гравюра, техники и приемы высокой и глубокой печати [Текст] / Йорди Катафал, Клара Олива. М: ООО «Художественно-педагогическое издательство», 2010 г. 160 с. - ISBN 978-5-98569-013.

2. Щипанов А.С. Юным любителям кисти и резца [Текст]/ Кн. для учащихся ст. классов А.С. Щипанов. 2-е изд., доп. и перераб. М.: Просвещение, 1981.416 с.

3. Фаворский В.А. Об искусстве, о книге, о гравюре. М.: Книга, 1986. 216 с.

4. Богачкина Л.Г. Линогравюра в школе / Л.Г. Богачкина, Б.М. Богачкин. М: Просвещение, 1983. 79 с.

5. Зорин Л.Г. Эстамп. Руководство по графическим и печатным техникам / Л.Г. Зорин. Москва: 2004. 200 с.

6. Pressing matters: the passion process; modern printmaking - issue 01 .

\section{Preferences}

1. Katafal J. Gravjura, tehniki i priemy vysokoj i glubokoj pechati [Tekst] / Jordi Katafal, Klara Oliva. M: OOO «Hudozhestvenno-pedagogicheskoe izdatel'stvo», 2010 g. 160 s. - ISBN 978-5-98569-013.

2. Shhipanov A.S. Junym ljubiteljam kisti i rezca [Tekst] / Kn. dlja uchashhihsja st. klassov A.S. Shhipanov. 2-e izd., dop. i pererab. M.: Prosveshhenie, 1981. $416 \mathrm{~s}$.

3. Favorskij V.A. Ob iskusstve, o knige, o gravjure. M.: Kniga, 1986. 216 s.

4. Bogachkina L.G. Linogravjura v shkole / L.G. Bogachkina, B.M. Bogachkin. M: Prosveshhenie, 1983. 79 s.

5. Zorin L.G. Estamp. Rukovodstvo po graficheskim i pechatnym tehnikam / L.G. Zorin. Moskva: 2004. 200 s.

6. Pressing matters: the passion process; modern printmaking - issue 01 . 